\title{
Effect of Preterm Birth on Postnatal Apolipoprotein and Adipocytokine Profiles
}

\author{
Gunnel Hellgren ${ }^{a, b}$ Eva Engström ${ }^{a}$ Lois E. Smith ${ }^{c}$ Chatarina Löfqvist ${ }^{b}$ \\ Ann Hellström ${ }^{b}$ \\ ${ }^{a}$ Department of Pediatrics, Institute of Clinical Sciences, and b Department of Ophthalmology, Institute of Neuroscience \\ and Physiology, Sahlgrenska Academy, University of Gothenburg, Gothenburg, Sweden; 'Department of Ophthalmology, \\ Boston Children's Hospital, Harvard Medical School, Boston, Mass., USA
}

\section{Key Words}

Prematurity · Apolipoproteins · Adipocytokines .

Multiplex assay

\begin{abstract}
Background: Critical metabolic changes preparing for ex utero life may occur at the fetal age of approximately 28-32 weeks, and preterm birth $<28$ weeks postmenstrual age (PMA) may affect these pathways. Children born $<28$ weeks often have poorer outcomes possibly due to a major shift in metabolism, including nutritional supply and a shift in lipid-transporting particles and lipid profile. This shift may occur in apolipoprotein and adipocytokine levels, which may influence metabolism. Objective: To determine whether there is a shift in apolipoprotein and adipocytokine levels in neonates born at a gestational age (GA) of 28 and 32 weeks, respectively. Methods: Blood samples from 47 infants (GA 32 weeks, $n=30$ and $G A 28$ weeks, $n=17$ ) were collected at birth and, in the GA28 group, also at PMA 32 weeks. Apolipoproteins A-1, A-2, $B, C-2, C-3$, and $E$ were analyzed, as well as adiponectin and leptin levels. Results: Serum levels of apolipoproteins A-1, C-2, $\mathrm{C}-3$, and $\mathrm{E}$ were lower at birth in the GA28 group compared to the GA32 group. Adiponectin and leptin levels were low at birth in the GA28 group. In the GA28 group 4 weeks after birth, leptin levels were still low, whereas adiponectin levels had increased to levels similar to those found at birth in the GA32
\end{abstract}

group. Apolipoprotein A-1, C-2, C-3, and E levels were negatively correlated with days receiving total parenteral nutrition. Conclusion: There are significant differences in apolipoprotein and adipocytokine levels, which can be associated with $G A$ and birth weight. The impact of these changes on neonatal and future morbidity remains to be determined.

(c) 2015 S. Karger AG, Basel

\section{Introduction}

According to WHO, preterm birth is defined as birth before 37 completed gestational weeks and can be further subdivided into extremely preterm ( $<28$ weeks), very preterm $(28$ to $<32$ weeks) and moderate or late preterm (32 to $<37$ weeks) [1]. There is a tremendous difference in risk associated with preterm birth depending on gestational age (GA) at birth, with a major shift occurring at about 28 weeks' postmenstrual age (PMA). Fatality risk is $28 \%$ when born at $<28$ weeks compared to $0.7 \%$ when born at 32-36 weeks. Also, morbidity rates are much higher when born at $<28$ weeks compared to those born at $>32$ weeks $[2,3]$. This shift in morbidity and mortality at 28 weeks' PMA suggests a major shift of metabolic processes at around 28 weeks of gestation.

The third trimester is the period when many organs undergo the fastest growth and development rates, and there

\section{KARGER 125}

(c) 2015 S. Karger AG, Base

1661-7800/15/1081-0016\$39.50/0

E-Mail karger@karger.com

www.karger.com/neo
Gunnel Hellgren

Department of Pediatrics, Institute of Clinical Sciences, Queen Silvia Children's Hospital Sahlgrenska Academy, University of Gothenburg, Växthuset

Rondvägen 15, SE-416 85 Gothenburg (Sweden)

E-Mail gunnel.hellgren@gu.se 
is a pronounced increase in the relative amount of adipose tissue. At birth, there is a major shift in nutritional supply, with a transition from substrate flow from the placenta towards an adaption to a high-fat milk diet. This process requires a shift in the synthesis and metabolism of lipidtransporting particles, the composition of which changes from that before birth. An altered lipid profile has been shown in preterm infants compared to term infants [4-7].

As lipids are the main structural components and therefore affect growth and development, lipid metabolism is of major importance in neonatal nutrition. There are many components involved in the complex lipid metabolism and transport system. One key group is apolipoproteins. Apolipoprotein A-1 (Apo A-1) is the main protein component of high-density lipoprotein (HDL) in plasma and promotes fat efflux, including cholesterol, from tissues to the liver. Apo A-2 is the second most abundant protein component of HDL. Apo B is the primary apolipoprotein of low-density lipoprotein (LDL), which carries cholesterol to tissues. Apo C-2 is a component of very low LDL and activates the enzyme lipoprotein lipase as a cofactor, whereas Apo C-3 inhibits lipoprotein lipase activity [8]. In the central nervous system, Apo $\mathrm{E}$ is involved in the transport delivery and clearing of lipids in the brain via Apo E receptors [9]. Both leptin [10] and adiponectin [11] levels in cord blood are associated with the lipid profile in neonates.

Our hypothesis for this study was that critical metabolic changes preparing for ex utero life may occur at the fetal age of approximately 28-32 weeks. The aim of the present study was to investigate apolipoprotein and adipocytokine levels in neonates born at GA 28 or 32 weeks, respectively.

\section{Patients and Methods}

\section{Ethical Considerations}

The protocol was approved by the Regional Ethical Review Board in Gothenburg, and the study was performed in accordance with the Declaration of Helsinki. Written informed consent was obtained from all parents.

\section{Study Participants and Sample Collection}

A total of 47 infants born at GA 27 weeks + 0 days to 28 weeks + 6 days $(n=17)$ or 32 weeks +0 days to 33 weeks +6 days $(n=30)$ were included in the study, referred to as the GA28 group and the GA32 group, respectively. Clinical characteristics of the study population are presented in table 1. From all infants, one serum sample was collected within $24 \mathrm{~h}$ after birth. From the GA28 group, an additional blood sample was collected at PMA 32 weeks. All serum samples were collected in connection with ordinary blood sampling. Exclusion criteria for participation in the study were serious malfor-
Table 1. Clinical and nutritional data

\begin{tabular}{lcc}
\hline Characteristics & $\begin{array}{c}\text { GA28, } \\
\text { at birth } \\
(\mathrm{n}=17)\end{array}$ & $\begin{array}{c}\text { GA32, } \\
\text { at birth } \\
(\mathrm{n}=30)\end{array}$ \\
\hline Preeclampsia & $6(35)^{1}$ & $4(14)^{2}$ \\
Antenatal steroids & $16(94)$ & $26(96)^{3}$ \\
Male gender & $8(47)$ & $18(60)$ \\
Multiple birth & $5(29)$ & $2(7)$ \\
Cesarean section & $15(88)$ & $16(53)$ \\
Apgar score 1 min & $9(5-9)$ & $9(5-10)$ \\
Apgar score 5 min & $9(7-10)$ & $10(7-10)$ \\
Apgar score 10 min & $10(7-10)$ & $10(9-10)$ \\
Total parenteral nutrition & $17(100)$ & $1(3)$ \\
Total parenteral nutrition, days & & \\
$\quad$ (min-max) & $5(3-13)$ & $0(0-2)$ \\
IRDS & $12(71)$ & $2(7)$ \\
BPD & $7(41)$ & 0 \\
PDAop & $1(6)$ & 0 \\
NEC & $1(6)$ & 0 \\
Proliferative ROP & $1(6)$ & 0 \\
IVH & $8(47)$ & $1(3)$ \\
\hline
\end{tabular}

Data are presented as $\mathrm{n}(\%)$ unless otherwise indicated. Apgar scores are presented as medians ( $\min -\max )$. IRDS $=$ Infant respiratory distress syndrome. $\mathrm{BPD}=$ bronchopulmonary dysplasia; $\mathrm{PDA}=$ patent ductus arteriosus; $\mathrm{NEC}=$ necrotizing enterocolitis; $\mathrm{ROP}=$ retinopathy of prematurity; IVH $=$ intraventricular hemorrhage.

${ }^{1}$ Missing data, $\mathrm{n}=1 .{ }^{2}$ Missing data, $\mathrm{n}=2 .{ }^{3}$ Missing data, $\mathrm{n}=3$.

mations, treatment with medicines other than antibiotics and blood or plasma transfusion before the first blood sample - or $<1$ week before the second blood sample was collected from the GA28 group. Serum samples were stored at $-70^{\circ} \mathrm{C}$ and not thawed until analysis.

\section{Feeding Regimen}

Enteral feeding with increasing amounts of breast milk was introduced early (2-48 h after birth). When full enteral feeding was not achieved, supplementary parenteral nutrition with amino acids and fat was given within the first days of life. For infants with a birth weight below $1,500 \mathrm{~g}$ the breast milk was fortified with 0.8 g protein $/ 100 \mathrm{ml}$ (gradually introduced over 1 week) from age 10 days until the infant weighed approximately $2 \mathrm{~kg}$. When the mother's milk was insufficient, unpooled donors' milk was given.

\section{Growth Measurement}

Standardized weight measurements were performed on the same day as blood sampling. A standard deviation score (SDS) for

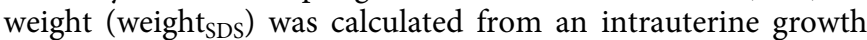
curve based on ultrasonically estimated fetal weights in Scandinavia [12]. Anthropometric data are shown in table 2.

\section{Multiplex Apolipoprotein Assay}

Serum samples were diluted 1:10,000 and Apo A-1, A-2, B, C-2, $\mathrm{C}-3$, and $\mathrm{E}$ levels were analyzed with a human apolipoprotein 6-plex assay (Millipore Corporation, Billerica, Mass., USA) ac- 
Table 2. Anthropometric data

\begin{tabular}{lll}
\hline Characteristics & GA28 $(\mathrm{n}=17)$ & GA32 $(\mathrm{n}=30)$ \\
\hline Birth weight, g & $1,005(555-1,155)$ & $1,982(1,365-2,495)$ \\
Birth weight SDS & $-1.54(-4.88$ to -0.10$)$ & $-0.60(-3.06$ to 1.68$)$ \\
Weight at PMA 32 weeks, g & $1,495(930-2,040)$ & \\
Weight at PMA 32 weeks, SDS & $-2.16(-4.91$ to -0.98$)$ & \\
Gain in height, g & $540(295-1,005)$ & \\
Gain in height, SDS & $-0.45(-1.27$ to 0.49$)$ & \\
\hline
\end{tabular}

Data are presented as medians (min-max).

Table 3. Serum levels of apolipoproteins and adipocytokines

\begin{tabular}{lcccccc}
\hline & $\begin{array}{l}\text { GA28, at birth } \\
(\mathrm{n}=17)\end{array}$ & $\begin{array}{l}\text { GA28, at 32 } \\
\text { weeks PMA }(\mathrm{n}=17)\end{array}$ & $\mathrm{p}_{1}$ & $\begin{array}{l}\text { GA32, at birth } \\
(\mathrm{n}=30)\end{array}$ & $\mathrm{p}_{2}$ & $\mathrm{p}_{3}$ \\
\hline Apo A-1, $\mu \mathrm{g} / \mathrm{ml}$ & $670(345-873)$ & $1,353(738-3,693)$ & $<0.001$ & $894(563-1,139)$ & $<0.001$ & $<0.001$ \\
Apo A-2, $\mu \mathrm{g} / \mathrm{ml}$ & $166(78-254)$ & $303(170-910)$ & $<0.01$ & $178(128-273)$ & n.s. & $<0.001$ \\
Apo B, $\mu \mathrm{g} / \mathrm{ml}$ & $16(0-1021)$ & $320(0-1,383)$ & $<0.01$ & $8(0-629)$ & n.s. & $<0.001$ \\
Apo C-2, $\mu \mathrm{g} / \mathrm{ml}$ & $31(7-77)$ & $56(32-161)$ & $<0.001$ & $56(17-88)$ & $<0.001$ & n.s. \\
Apo C-3, $\mu \mathrm{g} / \mathrm{ml}$ & $53(6-153)$ & $99(63-238)$ & $<0.001$ & $134(29-248)$ & $<0.001$ & n.s. \\
Apo E, $\mu \mathrm{g} / \mathrm{ml}$ & $72(20-170)$ & $76(38-188)$ & n.s. & $96(19-241)$ & $<0.05$ & n.s. \\
Adiponectin, $\mu \mathrm{g} / \mathrm{ml}$ & $1.8(0.6-14.1)$ & $16.6(4.3-77.3)$ & $<0.001$ & $22.5(3.7-50.6)$ & $<0.001$ & n.s. \\
Leptin, $\mathrm{ng} / \mathrm{ml}$ & $0.06(0.00-1.00)$ & $0.01(0.00-2.40)$ & n.s. & $0.63(0.00-6.48)$ & $<0.01$ & $<0.01$ \\
\hline
\end{tabular}

Data are presented as medians (min-max). $\mathrm{p}_{1}$ : p value GA28 group at birth vs. GA28 group at PMA 32 weeks; $\mathrm{p}_{2}$ : $\mathrm{p}$ value GA28 group at birth vs. GA32 group at birth; $\mathrm{p}_{3}$ : $\mathrm{p}$ value GA28 group at PMA 32 weeks vs. GA32 group at birth. n.s. = Nonsignificant.

cording to the manufacturer's instructions. Samples were analyzed on a Bio-Plex 200 instrument (Bio-Rad Laboratories, Hercules, Calif., USA) with Bio-Plex Manager 6.1 software. Doublet discriminator gate settings were set at 4,335-10,000 in accordance with Bio-Plex Manager instructions.

\section{ELISA Analyses}

Leptin. Serum samples were diluted 1:5, and leptin levels were assayed with a human leptin ELISA kit (Mediagnost, Reutlingen, Germany). Intra-assay coefficients of variation (CVs) were $3.0 \%$ at $5.2 \mathrm{ng} / \mathrm{ml}$ and $4.1 \%$ at $13.8 \mathrm{ng} / \mathrm{ml}$, and the interassay CV was $20.2 \%$ at $6.7 \mathrm{ng} / \mathrm{ml}$. The functional sensitivity limit of the assay was $0.3 \mathrm{ng} / \mathrm{ml}$.

Adiponectin. Serum samples were diluted 1:306, and adiponectin levels were assayed with a human adiponectin ELISA kit (Mediagnost). Intra-assay CVs were $3.8 \%$ at $3.9 \mu \mathrm{g} / \mathrm{ml}$ and $4.7 \%$ at $13.1 \mu \mathrm{g} / \mathrm{ml}$, and the interassay CV was $16.3 \%$ at $9.9 \mu \mathrm{g} / \mathrm{ml}$. For values $>80 \mu \mathrm{g} / \mathrm{ml}$, samples were further diluted with assay diluent, and the assay was repeated so that the results fell within the range.

\section{Statistics}

Basic data analyses on multiplex data were performed with BioPlex Data Pro software. Additional data analyses were performed with SPSS software version 20. All statistical analyses were per- formed with nonparametric tests. Differences between independent groups were performed by the Mann-Whitney $U$ test and between related groups by the Wilcoxon signed-rank test. Correlation analyses were performed by the Spearman rho test. The level of significance was set at $\mathrm{p}<0.05$.

\section{Results}

\section{Apolipoprotein Serum Levels Measured by Multiplexing}

Apo A-1, C-3, C-2, and E levels were lower at birth in the GA28 group compared to at birth in the GA32 group. In the GA28 group, Apo A-1, A-2, B, C-2, and C-3 levels increased from birth to postnatal age (PNA) 4 weeks (PMA 32 weeks). When apolipoprotein levels in serum collected from the GA28 group at PNA 4 weeks (PMA 32 weeks) were compared to levels at birth in the GA32 group, Apo A-1, A-2 and B levels were higher in the GA28 group. Detailed information on serum levels are presented in table 3.
18
Hellgren/Engström/Smith/Löfqvist/ Hellström 


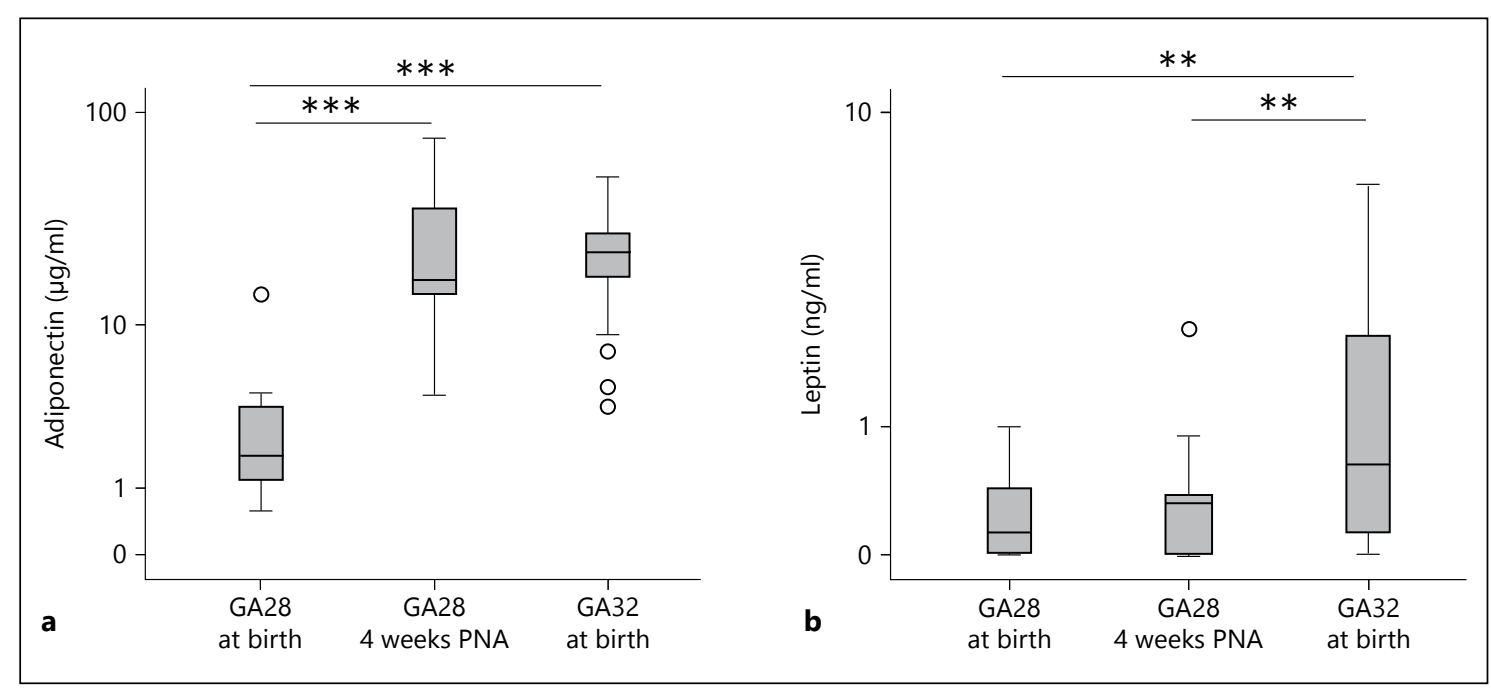

Fig. 1. Serum levels of adiponectin (a) and leptin (b), as measured by ELISA. ${ }^{* *} \mathrm{p}<0.01 ;{ }^{* *} \mathrm{p}<0.001$.

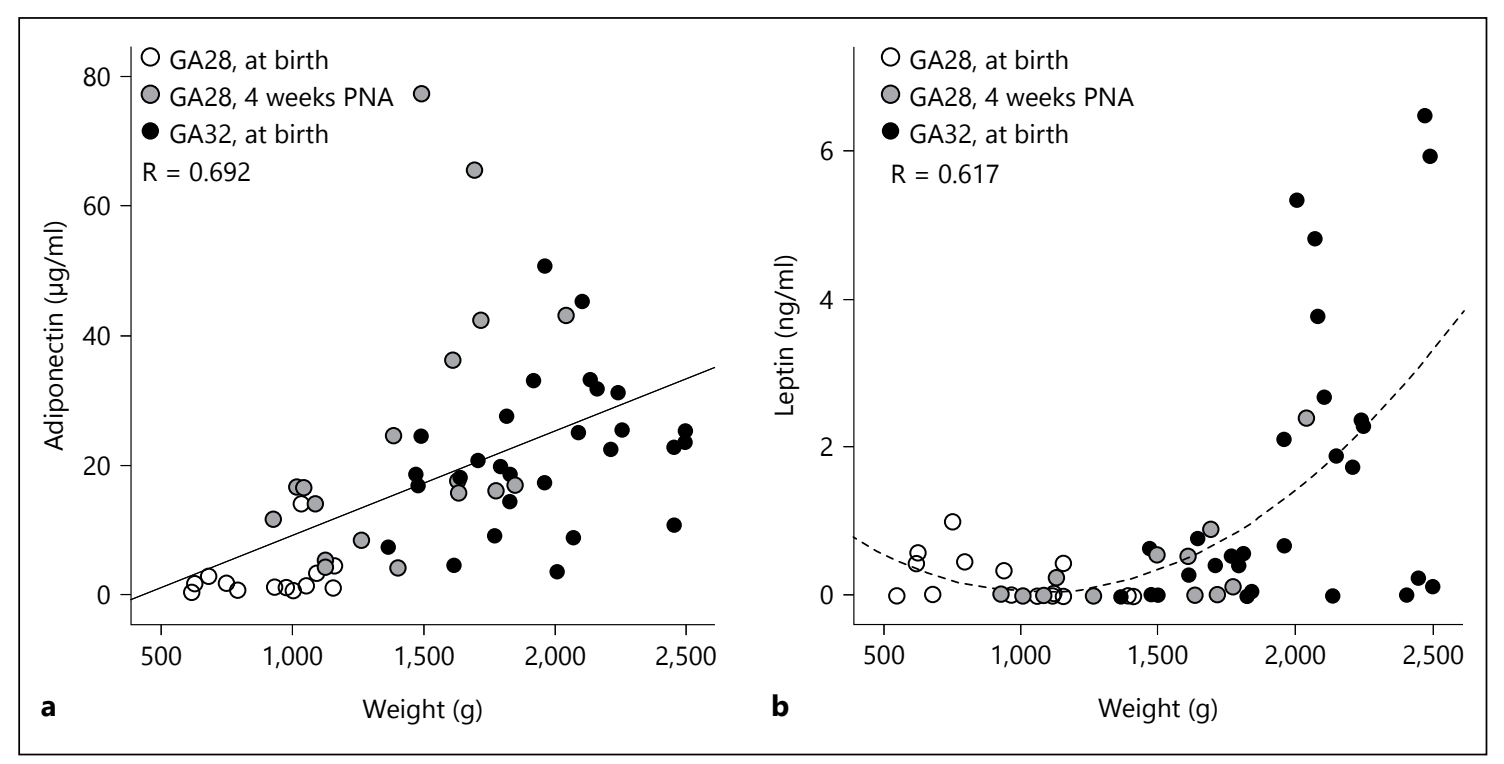

Fig. 2. Correlation between weight and serum levels of adiponectin (a) and leptin (b), as measured by ELISA. ** $\mathrm{p}<0.01 ; * * * \mathrm{p}<0.001$.

Serum Levels of Adipocytokines

Adiponectin. Serum levels of adiponectin at birth were lower in the GA28 group compared to at birth in the GA32 group. At PNA 4 weeks (PMA 32 weeks) in the GA28 group, levels increased similar to those found at birth in the GA32 group (fig. 1a; table 3). There was a positive correlation between weight and adiponectin levels $(\mathrm{r}=0.692$, $\mathrm{p}<0.001$; fig. 2a).

Leptin. In the GA28 group, serum levels of leptin were significantly lower, both at birth and at PNA 4 weeks
(PMA 32 weeks), compared to levels at birth in the GA32 group (fig. 1b; table 3 ). Leptin levels were nonlinearly correlated with weight $(\mathrm{r}=0.617, \mathrm{p}<0.001)$. However, leptin levels exceeding $1 \mathrm{ng} / \mathrm{l}$ could not be detected in any child weighing $<1,900 \mathrm{~g}$ (fig. 2b).

\section{Growth and Parenteral Nutrition in Relation to} Apolipoprotein and Adipocytokine Levels

Weight at birth for both groups and at PMA 32 weeks in the GA28 group are presented in table 2. In summary, 
Table 4. GA28 group: growth and parental nutrition in relation to weight, apolipoprotein and adipocytokine levels

\begin{tabular}{|c|c|c|c|}
\hline & At birth, $r$ & $\begin{array}{l}\text { At PMA } 32 \\
\text { weeks, r }\end{array}$ & $\begin{array}{l}\text { Change } \\
\text { from birth } \\
\text { to } 32 \text { week's } \\
\text { PMA, r }\end{array}$ \\
\hline \multicolumn{4}{|l|}{ Gain in weight } \\
\hline Total parental nutrition & -0.46 & -0.46 & \\
\hline Apo A-1 & -0.07 & 0.35 & 0.22 \\
\hline Apo A-2 & -0.14 & 0.28 & 0.34 \\
\hline Apo B & -0.37 & 0.29 & $0.58^{*}$ \\
\hline Apo C-2 & $0.54^{*}$ & 0.05 & -0.23 \\
\hline Apo C-3 & 0.43 & 0.32 & -0.08 \\
\hline Apo $\mathrm{E}$ & 0.37 & -0.35 & -0.33 \\
\hline Leptin & $-0.67^{* *}$ & 0.39 & $0.58^{*}$ \\
\hline Adiponectin & 0.49 & 0.28 & 0.14 \\
\hline \multicolumn{4}{|l|}{ Parental nutrition } \\
\hline Weight & -0.11 & -0.30 & -0.46 \\
\hline Weight $_{\text {SDS }}$ & -0.28 & -0.31 & 0.10 \\
\hline Apo A-1 & $-0.55^{*}$ & 0.01 & 0.27 \\
\hline Apo A-2 & -0.45 & 0.13 & 0.28 \\
\hline Apo B & -0.33 & 0.02 & 0.13 \\
\hline Apo C-2 & $-0.75^{* * *}$ & -0.21 & -0.23 \\
\hline Apo C-3 & $-0.72^{* * *}$ & -0.18 & $-0.53^{*}$ \\
\hline Apo E & $-0.70^{* *}$ & 0.12 & 0.39 \\
\hline Leptin & 0.15 & -0.37 & -0.40 \\
\hline Adiponectin & -0.31 & -0.13 & -0.17 \\
\hline
\end{tabular}

infants in the GA28 group were born at lower weights than infants in the GA32 group - birth weight $(\mathrm{p}<0.001)$ and birth weight $\mathrm{SDS}_{\mathrm{S}}(\mathrm{p}<0.01)$. Weight gain in grams and duration of total parenteral nutrition in relation to apolipoprotein and adipocytokine levels in the GA28 group are presented in table 4 . There were no correlations with weight gain in SDS.

\section{Discussion}

In summary, this study found lower levels of most apolipoproteins as well as adiponectin and leptin at birth in very preterm infants than in moderately preterm infants. In very preterm infants, adiponectin levels increased 4 weeks after birth, whereas leptin levels remained low. Leptin levels were undetectable or very low in all infants weighing $<1,900 \mathrm{~g}$, independent of GA at birth.

Lipid metabolism has an important role in fetal development during the last stages of gestation. During fetal life, the main nutritional sources are glycogen and fat, which are supplied by a substrate flow from the placenta to the fetus. At birth, adaption to a high-fat milk diet involves shifts in the synthesis, metabolism and composition of lipid-transporting particles [13]. The main energy sources during this period are fatty acids and ketone bodies. Fatty acids needed locally are provided by circulating lipids that contain a high proportion of apolipoproteins. Apolipoproteins control the cellular uptake of lipoproteins and work as lipid transport proteins and coenzymes. Synthesis of apolipoproteins is controlled by several factors, including dietary composition and hormones like insulin, glucagon and sex steroids. Thus, the expression of apolipoproteins is regulated by several hormones and pathways affected by preterm birth. In the present study, we found lower circulating levels of Apo A-1, C-2, C-3, and E in infants with a GA $<29$ weeks than in infants with a GA around 32 weeks. During pregnancy, intact lipid transfer across the placenta is crucial to secure a sufficient supply of essential fatty acids to the fetus. The placental transfer of fatty acids is increased during the second half of pregnancy in association with rapid fetal fat deposition [13].

In infants born very preterm, lipid metabolism might not be adapted to extrauterine life, with a consequent dysfunctional supply of essential fatty acids to different tissues [14]. A marked increase in very low LDL, HDL, and LDL triglycerides has been reported in cord blood around GA 32-34 weeks [6]. Some data support a neuroprotective role for Apo E $[15,16]$, whereas others found no relation between Apo E genotypes and neurodevelopmental outcome in preterm infants $[17,18]$. In this study, the levels of Apo E at birth in infants born at GA 28 weeks were still low 4 weeks after birth, which is interesting in the light of the high risk of neurocognitive impairment associated with prematurity $[2,17,18]$.

In line with our results, a positive correlation between Apo A-1 levels in cord blood and GA has been reported [19] - from $519 \mu \mathrm{g} / \mathrm{ml}$ at GA $21-26$ weeks to $869 \mu \mathrm{g} / \mathrm{ml}$ at GA 33-36 weeks before a plateau was reached until GA 41-43 weeks. Lane and McConathy [4] found that in cord blood, Apo A-2, C-2 and E levels were inversely correlated with GA, whereas Apo D was positively associated with GA. One reason for partially inconsistent results compared to our study could be group classification, since older preterm study groups were included in previous papers $[4,5]$.

In the GA28 group, we found a strong negative correlation between duration of total parenteral nutrition received and Apo A-1, C-2, C-3, and E levels at birth. As these apolipoproteins were low in infants born at GA 
$<29$ weeks we can speculate that low apolipoprotein levels at birth might reflect a more immature gut, even though gene expression was not investigated in this study. Positive effects on the HDL pattern after early enteral nutrition have previously been shown, and early enteral feeding facilitated a postnatal rise in Apo A-1, probably reflecting positive effects on gut maturation [20].

In humans, leptin plays a central role in maintaining the energy balance and regulation of energy homeostasis. Associations between leptin and lipid levels [21], as well as with factors involved in cholesterol metabolism [22], have been shown. However, the causal relationship between leptin and lipid metabolism has yet to be explained. Adiponectin has been implicated in the pathophysiology of insulin-mediated lipoprotein metabolism [23], and some studies [11], but not all [10], have shown an inverse correlation between adiponectin levels and LDL cholesterol in cord blood.

In line with our results, low fetal levels of leptin in preterm neonates have been reported - median $0.6 \mathrm{ng} / \mathrm{ml}$ until GA 34 weeks, and then a gradual increase to $3.5 \mathrm{ng} /$ $\mathrm{ml}$ at full term. However, the range was high [24]. In this study, there was a positive correlation between leptin levels and birth weight in infants born at GA 32 weeks but not in those born $<$ GA 29 weeks (data not shown). Change in leptin levels correlated positively with weight gain in grams, probably reflecting increased amounts of adipose tissue. Increasing adiponectin levels in cord blood, from GA 20 weeks to full term, have previously been shown approximately $5 \mu \mathrm{g} / \mathrm{ml}$ at GA 28 weeks and $15 \mu \mathrm{g} / \mathrm{ml}$ at GA 32 weeks [25]. In our study, adiponectin levels did not correlate with birth weight in either of the GA groups. Our data suggest that adiponectin levels start to increase shortly after birth. In contrast, leptin levels were still low at 4 weeks after birth in the GA28 group. Our data suggest that a weight above approximately $1,900 \mathrm{~g}$ is needed to observe increased leptin levels. This is in line with previous data suggesting that a relationship between leptin and body fat mass develops early in life [26], whereas the adiponectin system might be more related to GA [25].

The clinical significance of our findings with respect to the preterm infant's adaption to extrauterine life has to be further elucidated. In addition to the suggested role in gut maturity, there are links between apolipoproteins, adipocytokines and thermogenesis. In mice 4-5 days old, leptin reduced temperature loss after starvation [27], and in a genetic atherosclerotic mouse model adiponectin rescued Apo E-deficient mice from cold-induced lipolysis with elevated LDL levels. In contrast, no cold-induced effects on lipolysis and LDL levels were observed in Apo E-intact mice [28].

The lack of a control group born full term is a limitation of this study. However, the main purpose of the study was to compare circulating levels of selected factors between GA 28 and GA 32 weeks, a period in which important metabolic maturations preparing for ex utero life might occur. Being born $<$ GA 28 weeks or $>$ GA 32 weeks is in most countries in the developed world associated with a major difference in morbidity risk. Another limitation is that the GA32 group, due to discharge, was not followed up with a blood sample 4 weeks after birth. Thus, conclusions regarding postnatal changes in different preterm groups cannot be drawn.

From the present study, we conclude that there are significant differences at birth in circulating levels of apolipoproteins and adipocytokines between very preterm and moderately preterm infants. The impact of these findings has to be further elucidated in a larger cohort, where biochemical data and long-term morbidity is followed longitudinally and related to the lipid metabolism.

\section{Acknowledgments}

This study was supported by grants from the Research Foundation at the University of Gothenburg/Sahlgrenska University Hospital (ALFGBG-21611), the Swedish Medical Research Council (VR 2008-2842), the Wilhelm and Martina Lundgrens Vetenskapsfond, Kronprinsessan Margaretas Arbetsnämnd för Synskadade, and the Göteborg Medical Society, as well as NIH/NEI EY022275, EY017017 and P01 HD18655 (L.E.S.) and Lowy Medical Foundation. We acknowledge Ass. Prof. Aimon Niklason for his substantial contribution to the scientific outline of the project and Anne Rosenkvist, RN for coordinating blood samplings.

\section{Disclosure Statement}

The authors have no conflicts of interest to disclose.

References

Neonatology 2015;108:16-22 DOI: $10.1159 / 000381278$
Preterm Birth, Apolipoproteins and Adipokines

\footnotetext{
1 Blencowe H, Cousens S, Oestergaard MZ, Chou D, Moller AB, Narwal R, Adler A, Vera Garcia C, Rohde S, Say L, Lawn JE: National, regional, and worldwide estimates of preterm birth rates in the year 2010 with time trends since 1990 for selected countries: a systematic analysis and implications. Lancet 2012;379: 2162-2172.

2 Blencowe H, Lee AC, Cousens S, Bahalim A, Narwal R, Zhong N, Chou D, Say L, Modi N, Katz J, Vos T, Marlow N, Lawn JE: Preterm birth-associated neurodevelopmental impairment estimates at regional and global levels for 2010. Pediatr Res 2013;74(suppl 1):17-34.
} 
-3 Blencowe H, Lawn JE, Vazquez T, Fielder A, Gilbert C: Preterm-associated visual impairment and estimates of retinopathy of prematurity at regional and global levels for 2010 . Pediatr Res 2013;74(suppl 1):35-49.

4 Lane DM, McConathy WJ: Factors affecting the lipid and apolipoprotein levels of cord sera. Pediatr Res 1983;17:83-91.

5 Morillas JM, Molto L, Robles R, Gil A, Sanchez-Pozo A: Lipoproteins in preterm and small-for-gestational-age infants during the first week of life. Acta Paediatr 1992;81:774778.

6 Yonezawa R, Okada T, Kitamura T, Fujita H, Inami I, Makimoto $\mathrm{M}$, Hosono $\mathrm{S}$, Minato $\mathrm{M}$, Takahashi S, Mugishima H, Yamamoto T, Masaoka N: Very low-density lipoprotein in the cord blood of preterm neonates. Metabolism 2009;58:704-707.

7 Diaz M, Leal C, Ramon y Cajal J, Jimenez MD, Martinez H, Pocovi M, Grande F: Cord blood lipoprotein-cholesterol: relationship birth weight and gestational age of newborns. Metabolism 1989;38:435-438.

8 Mahley RW, Innerarity TL, Rall SC Jr, Weisgraber KH: Plasma lipoproteins: apolipoprotein structure and function. J Lipid Res 1984; 25:1277-1294.

-9 Ladu MJ, Reardon C, Van Eldik L, Fagan AM, Bu G, Holtzman D, Getz GS: Lipoproteins in the central nervous system. Ann NY Acad Sci 2000;903:167-175.

10 Nakano Y, Itabashi K, Maruyama T: Association between serum adipocytokine and cholesterol levels in cord blood. Pediatr Int 2009; 51:790-794.

-11 Bansal N, Charlton-Menys V, Pemberton P, McElduff P, Oldroyd J, Vyas A, Koudsi A, Clayton PE, Cruickshank JK, Durrington PN: Adiponectin in umbilical cord blood is inversely related to low-density lipoprotein cholesterol but not ethnicity. J Clin Endocrinol Metab 2006;91:2244-2249.
12 Marsal K, Persson PH, Larsen T, Lilja H, Selbing A, Sultan B: Intrauterine growth curves based on ultrasonically estimated foetal weights. Acta Paediatr 1996;85:843-848.

13 Herrera E, Amusquivar E: Lipid metabolism in the fetus and the newborn. Diabetes Metab Res Rev 2000;16:202-210.

14 Innis SM: Essential fatty acid transfer and fetal development. Placenta 2005;26(suppl A):S70-S75.

15 Kitagawa K, Matsumoto M, Kuwabara K, Takasawa K, Tanaka S, Sasaki T, Matsushita K, Ohtsuki T, Yanagihara T, Hori M: Protective effect of apolipoprotein $\mathrm{E}$ against ischemic neuronal injury is mediated through antioxidant action. J Neurosci Res 2002;68: 226-232.

16 Strittmatter WJ, Bova Hill C: Molecular biology of apolipoprotein E. Curr Opin Lipidol 2002;13:119-123.

17 Blackman JA, Gordish-Dressman H, Bao Y, Matsumoto JA, Sinkin RA: The apolipoprotein gene and recovery from brain injury among extremely preterm infants. Neonatology 2014;105:227-229.

18 Korja M, Ylijoki M, Lapinleimu H, Pohjola P, Matomaki J, Kusmierek H, Mahlman M, Rikalainen H, Parkkola R, Kaukola T, Lehtonen L, Hallman M, Haataja L: Apolipoprotein E, brain injury and neurodevelopmental outcome of children. Genes Brain Behav 2013;12: 348-352.

19 Parker CR Jr, Fortunato SJ, Carr BR, Owen J, Hankins GD, Hauth JC: Apolipoprotein A-1 in umbilical cord blood of newborn infants: relation to gestational age and high-density lipoprotein cholesterol. Pediatr Res 1988;23: 348-351.

20 Genzel-Boroviczeny O, Gobel Y, Koletzko B: Effect of early enteral feeding on apolipoprotein AI levels and high-density lipoprotein heterogeneity in preterm infants. Ann Nutr Metab 2002;46:121-127.
21 Gupta A, Gupta V, Agrawal S, Natu SM, Agrawal CG, Negi MP, Tiwari S: Association between circulating leptin and insulin resistance, the lipid profile, and metabolic risk factors in North Indian adult women. Biosci Trends 2010;4:325-332.

22 Hallikainen M, Kolehmainen M, Schwab U, Laaksonen DE, Niskanen L, Rauramaa R, Pihlajamaki J, Uusitupa M, Miettinen TA, Gylling H: Serum adipokines are associated with cholesterol metabolism in the metabolic syndrome. Clin Chim Acta 2007;383:126-132.

23 Lihn AS, Pedersen SB, Richelsen B: Adiponectin: action, regulation and association to insulin sensitivity. Obes Rev 2005;6:13-21.

24 Jaquet D, Leger J, Levy-Marchal C, Oury JF, Czernichow P: Ontogeny of leptin in human fetuses and newborns: effect of intrauterine growth retardation on serum leptin concentrations. J Clin Endocrinol Metab 1998;83: 1243-1246.

25 Martos-Moreno GA, Barrios V, Saenz de Pipaon M, Pozo J, Dorronsoro I, Martinez-Biarge M, Quero J, Argente J: Influence of prematurity and growth restriction on the adipokine profile, IGF1, and ghrelin levels in cord blood: relationship with glucose metabolism. Eur J Endocrinol 2009;161:381-389.

26 Tung WK, Lin SJ, Hwang YS, Wu CM, Wang $\mathrm{YH}$, Tsai WH: Association of cord plasma leptin with birth size in term newborns. Pediatr Neonatol 2009;50:255-260.

27 Blumberg MS, Deaver K, Kirby RF: Leptin disinhibits nonshivering thermogenesis in infants after maternal separation. Am J Physiol 1999;276:R606-R610.

28 Dong M, Yang X, Lim S, Cao Z, Honek J, Lu H, Zhang C, Seki T, Hosaka K, Wahlberg E, Yang J, Zhang L, Lanne T, Sun B, Li X, Liu Y, Zhang Y, Cao Y: Cold exposure promotes atherosclerotic plaque growth and instability via UCP1-dependent lipolysis. Cell Metab 2013; 18:118-129. 